\title{
O Conhecimento Morfológico da Criança na Escrita do Português Brasileiro ${ }^{1}$ \\ ARTIGO ORIGINAL
}

\author{
Jane Correa ${ }^{2}$ \\ Universidade Federal do Rio de Janeiro \\ Juliana Lugarinho \\ Secretaria Municipal de Saúde da Prefeitura do Município do Rio de Janeiro \\ Nicole Colucci \\ Instituto de Aplicação Fernando Rodrigues da Silveira, CAp- UERJ
}

\begin{abstract}
RESUMO - Examina-se o emprego do conhecimento morfológico por crianças do $3^{\circ}$. ao $5^{\circ}$. ano do ensino fundamental, analisando a grafia de terminações (morfemas) pronunciadas da mesma maneira, mas escritas diferentemente. Quatro grupos foram formados: (a) uso indiscriminado das formas de grafar as respectivas terminações, sugerindo o reconhecimento das diversas formas de escrevê-las, sem decidir convenientemente entre as mesmas; (b) preferência por uma das formas de grafar a terminação; (c) uso preferencial de outra forma de grafar a terminação; d) grafia convencional dos morfemas e o uso de informação morfológica. Embora progrida com a escolaridade, o uso da informação morfológica para a escrita de morfemas homófonos mostrou-se tardio, não estando concluído ao término da escola primária.
\end{abstract}

Palavras-chave: morfologia (linguística), ortografia, linguagem escrita

\section{Children's Knowledge of Written Morphology in Brazilian Portuguese}

\begin{abstract}
Brazilian 3rd to 5th grade children's use of morphological knowledge in spelling word endings which are pronounced the same (morphemes), but spelled differently, was analyzed. Four groups were formed: (a) spelling patterns used indiscriminately, suggesting children knew the morphemes had different representations, but were unable to decide between alternative spellings; (b) higher average score on one spelling form; c) higher average score on the alternative spelling form; (d) appropriately spelling of the word endings, indicating the use of written morphology. Although spelling improved with schooling, the use of morphological knowledge to disambiguate alternative spellings of similar sounding word endings is a late acquisition, which is not even completed by the end of primary school.
\end{abstract}

Keywords: morphology (linguistics), spelling, written language

Escrever de acordo com a norma consiste em compreender o princípio alfabético como as convenções da escrita ortográfica. Renunciando à ideia de que um grafema representa um e somente um fonema e à de que um fonema é somente representado por um determinado grafema, a criança necessita, então, integrar diversos saberes, habilidades e estratégias para poder escrever convencionalmente (Abbott \& Berninger, 1993; Correa \& Dockrell, 2007; Sénéchal, LeFevre, Smith-Chant, \& Colton, 2001).

Para escrever de acordo com a norma ortográfica no Português Brasileiro (Lemle, 1986; Morais, 2005), a criança deve notar que há grafias que: (a) variam em função da posição do fonema ou do grafema na palavra - exemplo: letra $r \mathrm{em}$ rato e caro; (b) são determinadas em nível morfossintático, como, por exemplo, o emprego da letra $r$ para marcar o infinitivo dos verbos em expressões que são omitidas na

1 Agradecemos ao CNPq e à FAPERJ - Edital Cientista do Nosso Estado pelo apoio concedido, sem o qual a realização deste trabalho não teria sido possível. Agradecemos a Secretaria Municipal de Educação do Município do Rio de Janeiro e a $2^{\mathrm{a}}$. CRE pela cooperação, às crianças e seus professores pelo muito que nos ensinaram acerca do aprendizado da escrita e à Camila Roque pela sua participação na coleta e tabulação dos dados.

2 Endereço para correspondência: Instituto de Psicologia - UFRJ, Avenida Pasteur, 250, Urca, Rio de Janeiro, RJ, Brasil. CEP: 22.290-902. E-mail: jane.correa@pq.cnpq.br fala; (c) são irregulares, ou seja, não há regularidades em níveis fonológico ou morfológico que possam determinar a grafia de uma palavra, quando, por exemplo, as letras $x$ e $c h$ concorrem para a representação do fonema $/ \mathrm{g} / \mathrm{em}$ um mesmo contexto (xale e chave).

$\mathrm{O}$ entendimento do princípio alfabético e o domínio das correspondências regulares entre fonema e grafema e viceversa estão relacionados ao desenvolvimento das habilidades de consciência fonológica, ou seja, das habilidades de segmentação e de análise da linguagem oral em diversos constituintes fonológicos assim como da manipulação de tais elementos. Há também evidências empíricas que associam o domínio das regularidades ortográficas relacionadas a variações do contexto grafofonêmico (regularidades de posição ou regularidades de contexto) ao desenvolvimento da consciência fonológica (Meireles \& Correa, 2005; Rego \& Buarque, 1997).

Embora o Português Brasileiro seja uma língua relativamente transparente no que se refere à relação grafema-fonema, as suas regularidades ortográficas, como anteriormente descritas, não estão limitadas ao nível fonológico da língua. Existem, ambiguidades na escrita que só poderão ser resolvidas por meio do conhecimento morfológico. Na construção formada por auxiliar + infinitivo do verbo principal (como em vamos brincar), o marcador do infinitivo é omitido na fala, mas não o é na escrita. A grafia 
convencional desse tipo de expressão na escrita é um exemplo de regularidade de natureza morfológica (Morais, 2005).

O emprego da morfologia por crianças nos anos iniciais de aprendizado da linguagem escrita é, ainda, objeto de debate (Deacon, 2008). Por um lado, discute-se a hipótese de que a criança, desde cedo, possa fazer uso da morfologia na escrita (McCutchen \& Stull, 2015; Treiman \& Cassar, 1996). De outro lado, hipotetiza-se que o emprego da morfologia pelas crianças na escrita é mais tardio (Nunes, Bryant, \& Bindman, 1997a, 1997b).

Em favor da primeira hipótese, aparecem estudos que examinam contextos restritos de escrita de palavras, como, por exemplo, a escrita somente da raiz das palavras, ou seja, do morfema comum às palavras de um determinado grupo lexical (Deacon \& Bryant, 2006a, 2006b; Kemp, 2006; Treiman \& Cassar, 1996). A associação entre a morfologia e a escrita ortográfica seria feita tão logo a criança começasse a ler e a escrever (Deacon, 2008).

Em relação à segunda hipótese, evidências empíricas vêm de estudos transversais (Carlisle, 1988; Sterling, 1983) e longitudinais (Nunes et al., 1997a, 1997b). A ênfase da investigação está no padrão de desenvolvimento de estratégias usadas na escrita, como das habilidades que possam explicar o seu emprego. Assim, o emprego de estratégia morfológica na escrita se mostraria posterior ao uso de outras estratégias como a alfabética e a lexical (Nunes et al., 1997a, 1997b).

Em ambos os casos, as evidências empíricas são oriundas, em sua grande maioria, de investigações em língua inglesa (Deacon, 2008). Do ponto de vista fonológico, o inglês é uma língua bastante irregular. O uso de estratégias fonológicas na escrita do inglês sofre, portanto, sérias limitações, o que impõe o recurso a estratégias de escrita de outra natureza (Correa, Maclean, Meireles, Lopes \& Glockling, 2007). No Português Brasileiro, por outro lado, há uma expressiva influência da fonologia tanto para a leitura (Correa, 2014), como para a escrita (Correa et al, 2007). Nesse sentido, uma contribuição importante para o exame do uso da morfologia na escrita poderia vir de investigações realizadas em ortografias relativamente transparentes, ou seja, que apresentem regularidades de natureza fonológica e que, ao mesmo tempo, possuam estrutura morfológica complexa, como é o caso do Português Brasileiro.

As pesquisas realizadas no Português Brasileiro visam, em sua maioria, determinar, quer na leitura, quer na escrita, a importância da consciência morfológica independentemente da influência exercida pela consciência fonológica (Guimarães, 2005, 2011). A escrita, no caso, é avaliada em relação ao desempenho ortográfico da criança, não sendo particularizada a grafia de regularidades morfológicas da língua (Mota, Anibal, \& Lima, 2008). Por meio de ditado, é examinada a escrita de palavras como de texto. Em menor número, estão os estudos acerca do desenvolvimento da consciência morfológica em crianças e da validade e fidedignidade das tarefas empregadas para avaliação desa habilidade (Mota, 2012a; Mota et al., 2008; Mota, Santos, \& Guimarães, 2014). Estudos que investigam especificamente a grafia de regularidades morfológicas pelas crianças são ainda em menor frequência. A escrita das crianças é examinada de duas formas: (a) por meio de palavras morfologicamente complexas e de palavras pseudoprefixadas (Miranda \& Mota, 2011); (b) pela escrita de regularidades morfológicas da língua (Meireles \& Correa, 2006; 2005).

No Português Brasileiro, a investigação do papel da consciência morfológica para o aprendizado da escrita tem sido objeto de um número crescente de investigações (Cardoso, Leandro, \& Vidigal de Paula, 2010; Guimarães \& Vidigal de Paula, 2010; Mota, 2012b). Encontram-se evidências empíricas de que a consciência morfológica tem uma contribuição independente da consciência fonológica para o domínio do sistema de escrita por crianças brasileiras (Mota, 2008; Mota et al., 2008). No entanto, a extensão de seu efeito como também o quão cedo a criança faz uso desse conhecimento ainda necessitam de um corpo maior de evidências empíricas.

O presente estudo pretende, então, examinar o emprego da morfologia na escrita de regularidades morfológicas por crianças brasileiras com escolaridade entre o $3^{\circ}$. ano e o $5^{\circ}$. ano do ensino fundamental. $\mathrm{O} 3^{\circ}$. ano finaliza o processo de alfabetização, encerrando, assim, um ciclo de ensino que tem como foco o aprendizado do sistema de escrita. $\mathrm{O} 5^{\circ}$. ano, por seu turno, marca o final do primeiro ciclo do ensino fundamental, em outros termos, a antiga escola primária. Intentamos, assim, examinar o emprego da morfologia na escrita segundo as diferentes etapas da escolaridade no ensino fundamental como sua possível variação e padrão de desenvolvimento.

No Português, a terminação /eza/ é escrita $e z a$, quando em morfema derivacional formador de substantivos abstratos (beleza, pobreza), ou esa, quando em morfema empregado na geração de forma feminina como em baronesa e norueguesa. Por sua vez, a terminação /ise/ é escrita ice, na grafia de morfema derivacional usado em substantivo abstrato (velhice, chatice) ou isse, na grafia da sequência de morfemas flexionais -isse (-i, vogal temática + -sse, morfema modo temporal do pretérito perfeito do subjuntivo), como, por exemplo, para o subjuntivo (partisse). Nesses casos, estratégias de natureza fonológica seriam de pouca utilidade para a criança na solução da ambiguidade apresentada na escrita de tais terminações. O emprego desses morfemas em palavras de baixa frequência (Pinheiro, 1996) foi utilizado como estratégia de controle para o emprego de estratégia lexical na escrita, de forma a permitir a grafia de tais terminações por meio do emprego de estratégia de natureza morfológica.

\section{Método}

\section{Participantes}

Concordaram em participar da pesquisa 191 crianças, estando 64 no $3^{\circ}$ ano (idade média $=8$ anos e 5 meses), 63 no $4^{\circ}$. ano (idade média $=9$ anos e 6 meses) e 64 no $5^{\circ}$. ano (idade média $=10$ anos e 8 meses) de uma escola da rede pública de ensino do Rio de Janeiro, em um bairro de nível socioeconômico médio. A realização da pesquisa foi autorizada pela Secretaria Municipal de Educação e pela equipe pedagógica da própria escola. A participação das 
crianças foi autorizada pelos responsáveis, que assinaram o Termo de Consentimento Livre e Esclarecido.

\section{Procedimentos}

Foram feitos ditados de trissílabos de baixa frequência (Pinheiro, 1996), incluindo palavras contendo os morfemas - esa (duquesa, freguesa, tigresa, chinesa) e -eza, (riqueza, tristeza, pobreza, limpeza) e os morfemas -ice (chatice, meiguice, velhice, burrice) e a sequência de morfemas -isse, (ouvisse, cumprisse, fugisse, sumisse). As palavras foram distribuídas em quatro diferentes listas de ditados em meio a outras palavras, de forma que as crianças não pudessem encontrar um padrão de escrita que pudesse ser repetido.

\section{Resultados}

O exame das transgressões ortográficas realizadas pelas crianças nos contextos críticos, ou seja, na grafia das terminações /eza/ ou /ise/, foi realizado por meio da Análise de Agrupamentos (Cluster Analysis). De acordo com essa análise, as crianças poderiam ser distribuídas em quatro grupos segundo as grafias produzidas respectivamente para a terminação /eza/, no emprego dos morfemas -esa e -eza ou para a grafia da terminação /ise/ pelo emprego dos morfemas -ice e a sequência de morfemas-isse.

\section{Terminação /eza/ e a Grafia dos Morfemas}

A Tabela 1 apresenta a frequência média de acertos em cada um dos quatro grupos gerados pela Análise de Agrupamentos (Cluster Analysis) para a grafia dos morfemas eza e esa. A análise contrastiva dos escores nas grafias dos respectivos morfemas permitiu que os quatro grupos fossem descritos como apresentados a seguir.

No grupo 1, foram reunidas as crianças que usam sem preferência as letras $z$ e $s$ para grafar o fonema /z/

Tabela 1. Proporção média de acertos nas grafias da terminação leza/ segundo os grupos resultantes da Análise de Agrupamentos

\begin{tabular}{lccc}
\hline & & \multicolumn{2}{c}{ Morfemas } \\
\cline { 3 - 4 } & & EZA & ESA \\
\hline Grupo 1 & Média & 0,14 & 0,16 \\
$n=16)$ & DP & 0,13 & 0,13 \\
Grupo 2 & & & \\
$(\mathrm{n}=39)$ & Média & 0,75 & 0,21 \\
& DP & 0,19 & 0,2 \\
Grupo 3 & & & \\
$(\mathrm{n}=75)$ & Média & 0,11 & 0,8 \\
& DP & 0,12 & 0,19 \\
Grupo 4 & & & 0,81 \\
$(\mathrm{n}=61)$ & Média & 0,66 & 0,16 \\
\hline
\end{tabular}

na terminação /eza/, o que indica que elas reconhecem a existência de mais de uma forma de representação para esse fonema. Neste momento, a criança ainda não conseguiu formular uma regra que lhe permita gerar as grafias dos morfemas -eza e -esa de forma convencional. Como consequência, a criança obtém baixos escores de acerto na grafia de ambos os morfemas.

O segundo grupo reúne as crianças cuja representação do fonema $/ z /$ é feita preferencialmente pela letra $z$. Tal resultado é indicativo de que as crianças baseiam-se na hipótese alfabética de que a letra $z$ é a representação prototípica do fonema em questão. Por conseguinte, grafam de forma convencional o morfema -eza. Por outro lado, como consequência, apresentam baixos escores na escrita convencional do morfema -esa.

Para as crianças do grupo 3, a letra s é a forma preferencial de representação do fonema/z/ na terminação/eza/. Embora a letra s seja prototipicamente associada ao fonema $/ \mathrm{s} /$, as crianças, pautadas na sensibilidade que possuem em relação à fonologia e ao entendimento da modificação do valor sonoro da letra segundo sua posição na palavra escrita, reconhecem a legitimidade da letra s na representação do fonema /z/. Dessa forma, o morfema esa é escrito de forma convencional. Por outro lado, são observados baixos escores na escrita, segundo a norma ortográfica, do morfema -eza.

No quarto e último grupo, o exame da Tabela 1 mostra que a proporção de acertos na escrita de ambos os morfemas é significativamente maior do que o esperado pelo uso indistinto das letras $s$ e $z$ para grafia do fonema /z/ na terminação/eza/. Tais escores sugerem que as crianças sejam capazes de fazer uso da informação morfológica para a grafia de ambos morfemas.

\section{A Escolaridade e a Grafia dos Morfemas}

De forma a examinar o emprego do conhecimento morfológico na escrita da criança do $3^{\circ}$. ano ao $5^{\circ}$. ano do Ensino Fundamental, examinamos a distribuição das crianças nos grupos resultantes da Análise de Agrupamentos segundo sua escolaridade (Tabela 2).

A porcentagem de crianças classificadas em cada um dos padrões de grafia variou consideravelmente segundo a escolaridade das crianças, indicando uma mudança no uso que a criança faz da informação morfológica na escrita da terminação /eza/ ao longo da escolaridade. Ao final do processo de alfabetização, existe um grupo de crianças

Tabela 2. Distribuição das Crianças de acordo com as grafias da terminação leza/ segundo os grupos resultantes da Análise de Agrupamentos em função da escolaridade (\%)

\begin{tabular}{lccc}
\hline & \multicolumn{3}{c}{ Escolaridade } \\
\cline { 2 - 4 } & $\begin{array}{c}\text { 3o ano } \\
(\mathrm{n}=64)\end{array}$ & $\begin{array}{c}40 \text { ano } \\
(\mathrm{n}=63)\end{array}$ & $\begin{array}{c}50 \text { ano } \\
(\mathrm{n}=64)\end{array}$ \\
\hline Grupo 1 & 6 & 14 & 5 \\
Grupo 2 & 38 & 10 & 14 \\
Grupo 3 & 41 & 41 & 36 \\
Grupo 4 & 15 & 35 & 45 \\
\hline
\end{tabular}


que demonstra poder fazer uso da morfologia na escrita de ambos os morfemas. Tais crianças representam apenas $15 \%$ do total das crianças entrevistadas no $3^{\circ}$. ano. No $4^{\circ}$. ano, a percentagem de crianças que empregam a informação morfológica em sua escrita dobra quando comparada ao ano anterior. Tal porcentagem, porém, equivale a um terço das crianças entrevistadas no $4^{\circ}$. ano. A percentagem de crianças no 5o. ano que seriam capazes de grafar consistentemente as terminações /eza/ em ambos os morfemas foi de $45 \%$, menos da metade das crianças entrevistadas no $5^{\circ}$. ano. Tais resultados indicam que, para a maioria das crianças, o emprego efetivo da informação morfológica na grafia da terminação /eza/ para os morfemas -eza e -esa não se realiza ao fim do primeiro segmento do ensino fundamental.

Importante observar que as crianças no $3^{\circ}$. ano apresentam a maior porcentagem relativa de grafias que indicam a generalização da letra $z$ para a grafia do fonema /z/ na terminação/eza/. Em outras palavras, pouco mais de um terço das crianças ao final do processo de alfabetização parecem ter a letra $z$ como a representação prototípica do fonema /z/ em qualquer contexto de sua ocorrência, sugerindo assim a predominância de uso de uma estratégia alfabética para a escrita dos morfemas.

Por outro lado, é também expressiva a porcentagem de crianças que do $3^{\circ}$. ao $5^{\circ}$. ano baseiam sua grafia da terminação /eza/ predominantemente no emprego da letra $s$. A porcentagem desse grupo varia pouco em três anos de escolaridade, perfazendo dois quintos das crianças entrevistadas em cada ano escolar. As crianças fazem uso de seu conhecimento de que a letra s pode ser também uma legítima representação do fonema / $\mathrm{z} /$ quando entre vogais e tendem a transpô-lo para a escrita da terminação /eza/. Tal conhecimento poderia ser atribuído ao reconhecimento de que o valor sonoro de uma letra pode variar segundo a sua posição na palavra. Conhecimento para o qual é plausível que a experiência da criança com palavras simples e de alta frequência como mesa ou casa possa ser tomada como referência. Seja qual for a explicação, o principal parâmetro para as crianças desse grupo permanece em nível fonológico.

Finalmente, um pequeno grupo de crianças chama atenção por não apresentarem um padrão específico para o emprego das letras $\mathrm{z}$ ou s na escrita de ambos os morfemas. Tais crianças reconhecem a existência de mais de uma forma de representação do fonema /z/ nesses contextos críticos. Tal conhecimento as faz renunciar ao emprego de uma estratégia alfabética nesses casos, sem que, no entanto, encontrem outra estratégia para resolver o conflito com que se deparam. Esse grupo de crianças não apresenta qualquer padrão sistemático para o emprego das letras, não se valendo quer de uma estratégia lexical, quer tendo sequências fonológicas como referência, como no caso da rima ou mesmo tendo como critério de frequência de letras. A escrita ortográfica, em casos de competição de letras para a representação de uma classe de fonemas em um mesmo contexto, parece a essas crianças um jogo de sorte (guessing game) ou de azar, segundo sua experiência de sucesso ou fracasso na escola.

\section{Terminação /ise/ e a Grafia dos Morfemas}

A proporção média dos escores de cada grupo gerados pela Análise de Agrupamentos para a grafia do morfema ice e da sequência de morfemas -isse é apresentada na Tabela 3. A análise contrastiva dos escores nas grafias dos morfemas permitiu a descrição dos grupos como apresentados a seguir.

Tabela 3. Proporção média de acertos nas grafias da terminação /isI/ segundo os grupos resultantes da Análise de Agrupamentos

\begin{tabular}{lccc}
\hline & & \multicolumn{2}{c}{ Morfemas } \\
\cline { 2 - 4 } & & EZA & ESA \\
\hline Grupo 1 & Média & 0,12 & 0,13 \\
& DP & 0,19 & 0,13 \\
Grupo 2 & Média & 0 & 0,75 \\
$(\mathrm{n}=51)$ & DP & 0 & 0,2 \\
& & & \\
Grupo 3 & Média & 0,91 & 0,24 \\
$(\mathrm{n}=17)$ & DP & 0,12 & 0,11 \\
& & & \\
Grupo 4 & Média & 0,52 & 0,74 \\
$(\mathrm{n}=30)$ & DP & 0,25 & 0,19 \\
\hline
\end{tabular}

As crianças do grupo 1 reconhecem a existência de mais de uma forma de representação para o fonema /s/. As letras majoritariamente empregadas para a representação do fonema são $c, s$ e ss. As crianças usam, sem qualquer critério aparente, essas formas de representação para grafar a terminação / ise/, obtendo, assim, baixos escores para a escrita tanto da sequência de morfemas -isse, quanto do sufixo -ice.

No grupo 2, estão as crianças que utilizam preferencialmente a letra c para representar o fonema /s/. É plausível que essas crianças empreguem seu conhecimento do nome da letra como representação possível do fonema em questão. É também possível que o emprego da letra c seja generalizado para a terminação /ise/ em função do morfema-ice ser extremamente produtivo (Quadros, 2011) e, por outro lado, do emprego do imperfeito do subjuntivo poder ser evitado na escrita dos escolares, sendo substituído pelo imperfeito do indicativo (Mexias-Simon, 2010). De uma forma ou de outra, as crianças escrevem convencionalmente apenas as palavras finalizadas com o morfema -ice. Esse é o grupo que concentra o maior número de crianças.

O grupo 3 reúne as crianças que empregam preferencialmente o dígrafo ss na grafia das palavras terminadas em /ise/. Neste momento, a criança tem provavelmente como referência o emprego da letra s por seu valor como representação não só prototípica como mais frequente do fonema $/ \mathrm{s} /$, aliada à utilização do dígrafo ss quando o referido fonema não está no início das palavras e entre vogais. Dessa forma, as crianças escrevem de forma convencional os verbos com terminação em isse. 
No grupo 4, as crianças escreveram, com maior frequência, ambos os morfemas de forma convencional. Tal desempenho expressa o recurso à informação de natureza morfológica.

\section{A Escolaridade e a Grafia dos Morfemas}

A Tabela 4 mostra o desempenho dos grupos para a terminação/ise/ e suas grafias segundo a escolaridade. Observa-se que a distribuição das crianças nos diferentes grupos variou consideravelmente segundo a escolaridade das crianças.

Tabela 4. Distribuição das Crianças de acordo com as grafias da terminação /isI/ segundo os grupos resultantes da Análise de Agrupamentos em função da escolaridade (em \%)

\begin{tabular}{lccc}
\hline & \multicolumn{3}{c}{ Escolaridade } \\
\cline { 2 - 4 } & $\begin{array}{c}\text { 3o ano } \\
(\mathrm{n}=51)\end{array}$ & $\begin{array}{c}\text { 4o ano } \\
(\mathrm{n}=43)\end{array}$ & $\begin{array}{c}50 \text { ano } \\
(\mathrm{n}=51)\end{array}$ \\
\hline Grupo 1 & 49 & 23 & 24 \\
Grupo 2 & 33 & 40 & 33 \\
Grupo 3 & 2 & 21 & 14 \\
Grupo 4 & 16 & 16 & 29 \\
\hline
\end{tabular}

A percentagem de crianças que generalizam a grafia da terminação /ise/ como ice mantém-se relativamente estável do $3^{\circ}$. ao $5^{\circ}$. ano, correspondendo a pelo menos um terço das crianças entrevistadas em cada ano escolar. Diferentemente do que ocorre com a grafia da terminação /eza/, o aumento de maior expressividade no percentual de crianças que empregam a informação morfológica para a terminação / ise/ ocorre apenas no $5^{\circ}$. ano. No entanto, a porcentagem de crianças que, nessa etapa da escolaridade, conseguiu fazer uso da informação morfológica foi inferior a um terço dos entrevistados. De maneira similar ao que aconteceu com a grafia dos sufixos -eza e -esa, o emprego da morfologia para a escrita do morfema ice ou da sequência de morfemas -isse não se completa ainda no $1^{\circ}$. segmento do ensino fundamental.

\section{Discussão}

O emprego da morfologia na escrita de crianças do $3^{\circ}$. ao $5^{\circ}$. ano do ensino fundamental foi examinado nos contextos críticos da terminação /eza/ para os morfemas -eza e -esa e da terminação/ise/ para o morfema ice e a sequência de morfemas -isse. O exame da escrita convencional dos morfemas para cada uma das terminações possibilitou reunir as crianças em grupos distintos. Os grupos formados poderiam ser assim descritos para ambas as terminações analisadas: (a) uso indiscriminado das formas de grafar as respectivas terminações, sugerindo que as crianças reconhecem que há formas diversas de escrever as respectivas terminações, porém são incapazes de decidir entre tais formas, parecendo que, por utilizarem a informação morfológica na escrita, o uso de uma ou outra letra não obedece, ainda, a um critério consistente; (b) preferência por uma das formas de grafar uma dada terminação, o que faz com que o número de acertos seja significativamente maior para a grafia de um morfema do que de outro; (c) uso preferencial por outra forma de grafar a respectiva terminação, o que gera um número significativamente maior de acertos na grafia do outro morfema; (d) obtenção de escores acima do nível de chance na grafia convencional dos morfemas, sugerindo o uso da morfologia para resolver a ambiguidade fonológica que se apresentava para cada uma das terminações analisadas.

Padrão semelhante na grafia de ambas as terminações foi encontrado na constituição dos grupos, ao longo da escolaridade. Isso sugere certa regularidade no emprego dos conhecimentos fonológicos e morfológicos pelas crianças. De maneira geral, as crianças no $3^{\circ}$. ano, ao se depararem com alguma ambiguidade a ser resolvida na grafia de ambas as terminações, valeram-se quer de seu conhecimento do nome das letras, quer da hipótese alfabética de regularidade absoluta entre fonema-grafema, escolhendo o grafema considerado prototípico para a representação do fonema. Tais procedimentos podem ser observados quer na representação sistemática do fonema /z/ pela letra z na terminação /eza/ ou, pela grafia do fonema /s/ pela letra c na terminação /ise/. O emprego dessas representações do conhecimento da escrita tende a diminuir com a escolaridade para as ambiguidades na escrita de morfemas de uso corrente. No entanto, quando o morfema não tem emprego corrente nos sintagmas que compõem a fala e a escrita das crianças, como no caso dos verbos no modo subjuntivo, tais estratégias tendem a prevalecer nas séries posteriores ao $3^{\circ}$. ano.

A generalização da representação do fonema /z/ pela letra s e a generalização da representação do fonema /s/ pelo grafema ss coincide com o reconhecimento da existência de regularidades de contexto. Um grupo de crianças nos mostra que o reconhecimento de que a grafia das palavras nem sempre obedecia ao princípio da regularidade absoluta entre fonema e grafema não leva a criança ao estabelecimento de uma regularidade ou de uma estratégia regular. Assim, observase que a criança não consegue resolver a ambiguidade na escrita das terminações avaliadas, não se decidindo por qualquer uma das representações de modo sistemático. Isso faz com que as crianças tenham um baixo número de acertos para a escrita de ambos os morfemas. A criança não consegue se decidir pela representação escrita dos morfemas porque não pode ainda estabelecer uma regularidade que lhe permita escrever os morfemas de forma convencional. A grafia aparece, então, como um jogo de adivinhação para a criança, já que tal ambiguidade não pode ser resolvida de forma satisfatória por ela.

O emprego sistemático do conhecimento morfológico surge para a maioria das crianças de forma consistente a partir do $4^{\circ}$ ano, quando as palavras formadas podem ser incluídas em sintagmas de uso corrente, como é o caso das palavras formadas com os morfemas eza e esa. Mesmo no caso desses morfemas, tal conhecimento não é empregado por quase metade das crianças do $5^{\circ}$. ano. No caso dos morfemas presentes em vocábulos empregados em sintagmas que não são usuais nos contextos de fala ou de escrita, como no caso do morfema isse, $70 \%$ das crianças no $5^{\circ}$. ano não conseguem 
ainda grafar tal morfema de acordo com a norma. Tais resultados mostram que, até o final do primeiro segmento do ensino fundamental, grande parte das crianças tenta resolver as ambiguidades na grafia basicamente em nível fonológico.

Em relação ao debate acerca de quando a morfologia seria efetivamente empregada pelas crianças em sua escrita, observamos que esse emprego não se efetiva ainda no último ano do primeiro segmento do ensino fundamental para a maioria das crianças analisadas. É possível que o uso da morfologia na escrita seja, portanto, uma aquisição tardia no Português Brasileiro (Nunes et al., 1997a, 1997b). Contudo, seria também possível que o uso da informação morfológica na escrita do Português Brasileiro não se efetivasse sequer em anos ulteriores de escolaridade (Deacon, 2008). No entanto, não podemos, ainda, decidir por qualquer uma das duas hipóteses com os dados existentes. Tal decisão só poderá ser tomada em se estendendo a investigação para os anos escolares que se seguem ao $5^{\circ}$. ano, isto é, ao término do $1^{\circ}$. segmento do ensino fundamental.

A realização de análise transversal baseada na comparação do desempenho médio das crianças em diferentes etapas de sua escolaridade fornece evidências empíricas acerca de um marco tardio no emprego da estratégia morfológica para a maioria das crianças de desenvolvimento típico (Nunes et al., 1997a, 1997b). No entanto, ao fazermos tal tipo de análise nos esquecemos de um grupo de crianças de desenvolvimento típico que começam, já no $3^{\circ}$. ano, a fazer uso dos conhecimentos morfológicos na escrita. A porcentagem de crianças que empregam de forma sistemática a informação morfológica na escrita para as terminações /eza/ e /ise/ é de cerca de $15 \%$. Dessa forma, é possível que o emprego de estratégia morfológica na escrita possa ocorrer mais cedo do que o esperado para um pequeno grupo de crianças. Tornase importante que investigações futuras possam examinar as habilidades linguístico-cognitivas dessas crianças, de forma que possamos entender a razão pela qual um grupo de crianças seja mais sensível à informação morfológica na escrita do que a média de seus pares.

O emprego do conhecimento morfológico na escrita da criança no Português do Brasil é, portanto, bem mais complexo do que se poderia imaginar a partir das evidências empíricas baseadas na análise do marco no desenvolvimento em que tal fato se torna possível. Embora as evidências oriundas de nosso estudo com as terminações /eza/e/ise/ contribuam para a discussão de modelos dicotômicos para o desenvolvimento do conhecimento morfológico na criança, investigações ulteriores são necessárias para outras regularidades morfológicas no Português Brasileiro.

Finalmente, quanto à relação entre a fonologia e a morfologia, seria possível que a eficácia do emprego do conhecimento fonológico pela criança seja um fator que retardaria o desenvolvimento de uma estratégia morfológica em línguas que apresentassem relativa transparência nas correspondências grafofonêmicas. Aárea necessita, ainda, de um corpo maior de evidências empíricas para que possamos melhor delinear o papel dos conhecimentos fonológico e morfológico na escrita do Português do Brasil.

\section{Referências}

Abbott, R. D., \& Berninger, V. W. (1993). Structural equation modeling of relationships among developmental skills and writing skills in primary- and intermediate-grade writers. Journal of Educational Psychology, 85, 478-508.

Cardoso, S.B., Leandro, D.S., \& Vidigal de Paula, F. (2010). Conhecimento morfológico derivacional e suas relações com o desempenho na escrita de palavras. Psicólogo inFormação, 12, 107-127.

Carlisle, J. F. (1988). Knowledge of derivational morphology and spelling ability in fourth, sixth and eighth grades. Applied Psycholinguistics, 9, 247-266.

Correa, J. (2014). O papel da consciência fonológica e da consciência morfológica na leitura de palavras no Português do Brasil. Em F. Viana, R. Ramos, E. Coquet \& M. Martins (Coords.), Actas do 10 . Encontro Nacional (8 ${ }^{\circ}$. Internacional) de Investigação em Leitura, Literatura Infantil e Ilustração (pp. 180-193). Braga: CIEC- Centro de Investigação em Estudos da Criança da Universidade do Minho (CDRom).

Correa, J., \& Dockrell, J. (2007). Unconventional word segmentation in brazilian children's early text production. Reading \& Writing, 20, 815-831.

Correa, J., Maclean, M, Meireles, E. S., Lopes, T. C., \& Glockling, D. (2007). Using spelling skills in Brazilian Portuguese and English. Journal of Portuguese Linguistics, 6, 61-82.

Deacon, S. H. (2008). The metric matters: Determining the extent of children's knowledge of morphological spelling regularities. Developmental Science, 11, 396-406.

Deacon, S. H., \& Bryant, P. E. (2006a). Getting to the root: Young writers' sensitivity to the role of root morphemes in the spelling of inflected and derived words. Journal of Child Language, 33, 401-417.

Deacon, S. H., \& Bryant, P. E. (2006b). This turnip's not for turning: Children's morphological awareness and their use of root morphemes in spelling. British Journal of Developmental Psychology, 24, 567-575.

Guimarães, S. R. K. (2011) Relações entre capacidade de segmentação lexical, consciência morfossintática e desempenho em leitura e escrita. Psicologia: Teoria e Pesquisa, 27(1), 2332.

Guimarães, S. R. K. (2005). Influência da variação linguística e da consciência morfossintática no desempenho em leitura e escrita. Interação em Psicologia, 9(2), 261-271.

Guimarães, S. R. K., \& Vidigal de Paula, F. (2010). O papel da consciência morfossintática na aquisição e no aperfeiçoamento da leitura e da escrita. Educação em Revista, 38, 92-111.

Lemle, M. (1987). Guia teórico do alfabetizador. Ática: São Paulo.

Kemp, N. (2006). Children's spelling of base, inflected and derived words: Links with morphological awareness. Reading and Writing, 19,737-765.

McCutchen, D., \& Stull, S. (2015). Morphological awareness and children's writing: Accuracy, error, and invention. Reading and Writing, 28, 271-289.

Meireles, E., \& Correa, J. (2006). A relação da tarefa de erro intencional com o desempenho ortográfico da criança considerados os aspectos morfossintáticos e contextuais da língua portuguesa. Estudos de Psicologia (Natal), 111(1), $35-43$. 
Meireles, E. S., \& Correa, J. (2005). Regras contextuais e morfossintáticas na aquisição da ortografia da língua portuguesa por criança. Psicologia: Teoria e Pesquisa, 21(1), 77-84.

Mexias-Simon, M. L. (2010). Tendências da língua coloquial observadas nos "erros" em trabalhos escolares. Mosaico Revista Multidisciplinar de Humanidades, 1(2), 11-20.

Miranda, L., \& Mota, M. M. P. E. (2011). Estratégias cognitivas de escrita do português do Brasil. Psico-USF, 16(2), 227-232.

Morais, A. G. (2005). A norma ortográfica do português: O que é? para que serve? Como está organizada? Em A. Silva, A. G. Morais \& K. L. R. Melo (Eds), Ortografia na sala de aula (pp.11-28). Belo Horizonte: Autêntica.

Mota, M. M. P. E. (2008). Algumas considerações a respeito do que as crianças sabem sobre a morfologia derivacional. Interação em Psicologia, 12(1), 115-123.

Mota, M. M. P. E. (2012a). Considerações metodológicas e conceituais sobre a construção de instrumentos de avaliação das habilidades metalinguísticas. Avaliação Psicológica, 11(1), 77-82.

Mota, M. M. P. E. (2012b). Explorando a relação entre consciência morfológica, processamento cognitivo e escrita. Estudos de Psicologia (Campinas), 29(1), 89-94.

Mota, M. M. P. E, Anibal, L., \& Lima, S. (2008). A morfologia derivacional contribui para a leitura e escrita no português? Psicologia: Reflexão e Crítica, 21(2), 311-318.
Mota, M. M. P. E, Santos, A. A. A., \& Guimarães, S. B. (2014). Evidências de validade e consistência interna de tarefas de analogia gramatical. Estudos de Psicologia (Natal), 19(4), 250-257.

Nunes, T., Bryant, P., \& Bindman, M. (1997a). Learning to spell regular and irregular verbs. Reading and Writing, 9, 427-449.

Nunes, T., Bryant, P., \& Bindman, M. (1997b). Morphological spelling strategies: Developmental stages and processes. Developmental Psychology, 33, 637-649.

Pinheiro, A. M. V. (1996). Contagem de frequência de ocorrência de palavras expostas a crianças na faixa pré-escolar e séries iniciais do $1^{\circ}$ grau. São Paulo: Associação Brasileira de Dislexia.

Quadros, E. S. (2011). Reflexões acerca da produtividade morfológica e de sua medição: Estudo de sufixos nominalizadores do português. ReVEL, 5, 186-198.

Rego, L. L. B., \& Buarque, L. L. (1997). Consciência sintática, consciência fonológica e aquisição de regras ortográficas. Psicologia: Reflexão e Crítica, 10(2), 199-217.

Sénéchal, M., LeFevre, J.A., Smith-Chant, B. L., \& Colton, K.V. (2001). On refining theoretical models of emergent literacy: The role of empirical evidence. Journal of School Psychology, 39, 439-460.

Sterling, C. M. (1983). Spelling errors in context. British Journal of Psychology, 74, 353-364.

Treiman, R., \& Cassar, M. (1996). Effects of morphology on children's spelling of final consonant clusters. Journal of Experimental Child Psychology, 63, 141-170.

Recebido em 30.08.2013

Primeira decisão editorial em 10.04.2015

Versão final em 10.04.2015

Aceito em 11.06.2015 